\title{
OPTIMAL POWER MANAGEMENT SYSTEM: A CONCEPTUAL DESIGN APPROACH
}

\author{
Pusapally Srinivas \\ B.Tech. Electrical \& Electronics \\ Karunya Institute of Technology \& Sciences \\ Coimbatore, Tamil Nadu, India
}

\author{
Lupthavisha Netam \\ B.Tech., Electrical \& Electronics \\ Karunya Institute of Technology \& Sciences \\ Coimbatore, Tamil Nadu, India
}

\begin{abstract}
Indian power management system is one among the largest power system networks in the world. India has a complex power transmission network which is monitored by multi-level integrated systems installed at many control levels. The Indian power sector is expected to grow both in its installed capacity and energy demand which makes it extremely essential to equip the country's power grid with novel applications of smart grid technologies. A technologically advanced architecture of power system could be beneficial to address issues at micro level and improve flexibility and robustness of the system. This research highlights technical advancements which are in practice in different countries. A conceptual design framework has been proposed which can be integrated with the existing energy management system and thus could potentially help in an improvised efficient monitoring and control system. Thus, help resolve chances of cascaded outages leading to blackouts.
\end{abstract}

Keywords - Power management system, power generation, power consumption, synchrophasor technology

\section{INTRODUCTION}

Power transmission is an essential part of the power sector and is as crucial as power generation; there is no value for generating power until the power reaches the end consumer. The huge amount of power generated in power station is to be transported over a long distance to the load centers to cater to the consumers with the help of transmission lines and transmission towers.

India's power transmission sector is mostly controlled by government - both the central and various state governments and various institutions to work in the transmission sector [1]. Evacuating power safely was the main focus of India's power transmission sector during the initial years. But as the need for electrification of more areas were realized for economic

\author{
Mohan Kumar Iyer \\ Head - Dept. of R\&D \\ Hillgrove Research Pvt. Ltd \\ Coimbatore, Tamil Nadu, India
}

growth, the role of transmission sector changed a lot. As with the changing scenario, the transmission sector started to move towards integrated system planning because generation capacities are distributed unevenly in different regions. Building on massive power transmission sector that uses a hybrid system of both High Voltage Alternating Current (HVAC) and High Voltage Direct Current (HVDC) over long distances addressed the issue. However, considering India's current 2020 population which is estimated at 1,380,004,385 people at midyear according to United Nations Organization (UNO) data which is expected to rise and grows until midcentury, reaching an estimate of 1.68 billion in the 2050s [2]; electricity demand is also expected to grow.

With the expectancy of growing population, aggregate electricity demand could grow roughly up to 2785 Tera Watthour (TWh); (high GDP, low efficiency) by 2030 ; Hence Smart grid technologies is the need of the hour. Energy supply market is undergoing deep transformation all across the world and with the ongoing economic crisis and shortage of natural resources, in comparison to the expectancy of growing demand of energy could be an alarming call for a more technologically advanced architecture of power system management. It could stand beneficial in not only addressing issues at remote area level such as heavy energy shortage, peak time shortage etc but could also help with threats and implications imposed from different meteorological conditions, pollution flashover, thunder damage etc. hence opening opportunities for improvements in quick decision making ability and enabling sound responses. An amalgamation of both centralized and decentralized coordination strategy can help address issues at micro level and improve deficiency in flexibility, transparency and robustness. The Indian power system has a wellestablished Energy Management System (EMS) with large number of Phasor Measurement Unit's (PMUs) across transmission network that uses synchrophasors to get accurate -time synchronized voltages, currents and frequency across the country at a sample rate of 25 times per second.

There is also rapid expansion of grid, Remote Terminal Unit's (RTU) and PMUs in response to the growing demand. 


\section{International Journal of Engineering Applied Sciences and Technology, 2020 \\ Vol. 5, Issue 8, ISSN No. 2455-2143, Pages 292-296 \\ Published Online December 2020 in IJEAST (http://www.ijeast.com)}

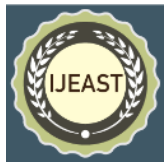

However a newly built system without proper integration with the existing energy management system will not only increase investment but also bring potential complexities into powergrid management. This can result in inconvenience of operation, inadequate data and low efficiency. This paper gives an insight to a proposed integrated architecture in sync with the existing energy management system that could help make independent decisions at micro level. It also discusses on the various technologies and practices adopted across the globe which could be potentially beneficial to strengthen India's capacity to meet the growing demand for electricity

\section{GROWING DEMAND FOR ELECTRICITY}

India is the world's third largest producer and third largest consumer of electricity [3]. The national grid has an installed capacity of 371 Giga Watt (GW) as on July 2020. Renewable Power Plants which also include large hydro-electric plants constitute around $35.86 \%$ of total installed capacity. During the fiscal year 2018-19, the gross electricity generated by utilities was $1,372 \mathrm{TWh}$ and the total electricity generation comprising both utilities and non-utilities was 1,547 TWh. The gross electricity consumption was 1,181 Kilo Watt hour (KWh) per capita [3]. The per capita consumption is low compared to most other countries despite having low tariff. The government's program 'Power for Al' worked greatly in providing distribution infrastructure to use the generated power to a maximum capacity was accomplished in 2018 ensuring uninterrupted power supply to all the households, industries and the commercial establishments.

The power capacity by 2030 is roughly estimated, that energy capacity in India by the year 2030 if the Gross Domestic Product (GDP) growth rate is projected at $6 \%$ is $4,13,385$ and at GDP projections at $9 \%$ is $5,09,967 \mathrm{MW}$ respectively.

As on 2017, 73 percent of electricity generation was based on coal. Due to its capital intensive and public good nature, electricity supply in India is highly regulated [3]. Electricity demand depends on various factors. India's GDP growth rate was expected to be at $7-8 \%$ by government sources and International Monetary Fund (IMF), to 5.5-6.5 by research institutions and private organizations. Electricity demand forecasts form the basis for supply (generation capacity and transmission and distribution (T\&D) infrastructure) planning at the central and state level [4]. Aggregate electricity demand could grow from 949 TWh in 2015 to between 2074 TWh (low GDP, high efficiency) and 2785 TWh (high GDP, low efficiency) by 2030 . In India, this exercise is carried out once in every few years by the Central Electricity Authority's (CEA) Electricity Power Survey (EPS). The recently released 19th EPS projects an electricity demand of $1743 \mathrm{TWh}$ (6.59 percent CAGR from 2017) and peak load of $299 \mathrm{GW}$ (6.32 percent CAGR) by 2027 [4].

NITI Aayog, private think tanks, and other multilateral organizations also undertake electricity projection exercises, at times using proprietary models. In system planning exercises, these projections are used as means to determine optimal system configuration under various scenarios, rather than as an end in itself. However, based on how models are set-up, significant insights can be obtained regarding the nature of relationships between macroeconomic drivers, technology options, policy levers and the responsiveness of electricity demand [4].

In the recent past, significant changes have taken place in the demand-supply dynamics as well as policy formulation in the electricity and related sectors. Energy and peak deficits have seen a secular decline, reducing to as low as 0.3 percent in the last quarter of 2016-17 (Central Electricity Authority, 20122018). Thermal power plants have been operating at low plant load factors (PLFs) owing to suppressed demand growth and utility - offtake, in addition to coal linkage issues. On the other hand, renewable energy (RE) capacity additions have picked up pace as new solar tariffs keep falling under reverse-bidding. In addition, the policies of central and state governments on 24/7 power for all, electricity market reforms, domestic manufacturing via 'Make in India', electric mobility, and energy efficiency will be instrumental in influencing the level and pattern of future demand [4].

With the boom in almost every sector, growth of GDP and the increasing population the per capita power consumption is also expected to increase.

Table 1: GDP CAGR by the year 2030

\begin{tabular}{|c|c|c|c|c|c|c|c|c|c|c|}
\hline \multirow{2}{*}{$\begin{array}{c}\text { GDP CAGR by } \\
2030\end{array}$} & \multirow{2}{*}{2015} & \multicolumn{3}{|c|}{$\begin{array}{c}\text { If GDP CAGR } \\
\text { is } 6.5 \%\end{array}$} & \multicolumn{3}{c|}{$\begin{array}{c}\text { If GP CAGR } \\
\text { is 7\% }\end{array}$} & \multicolumn{3}{c|}{ If GDP CAGR } \\
is 7.5\%
\end{tabular}

Source:indcom@tn.gov.in

\section{POWER GENERATION VERSUS CONSUMPTION}

The total installed capacity of India stands at 3, 71,977 MW. In which central sector companies like National Thermal Power Corporation Limited, National Hydroelectric Power Corporation, Power Grid Corporation of India Limited and others constitute around 94,027 MW i.e., $25.3 \%$ of total installed capacity. The state sector companies like west Bengal Electricity Board, Tamil Nadu Electricity Board, TSSPDCL of Telangana etc. constitute around 103,652 MW i.e., $27.9 \%$ of total installed capacity. The private players like Adani Power, Tata Power, Reliance Power and others 


\section{International Journal of Engineering Applied Sciences and Technology, 2020 \\ Vol. 5, Issue 8, ISSN No. 2455-2143, Pages 292-296 \\ Published Online December 2020 in IJEAST (http://www.ijeast.com)}

contribute around $174,298 \mathrm{MW}$ of the total installed capacity i.e. about $46.95 \%$ of total installed capacity as on 31July 2020 . The major source of power generation in India is the Thermal energy which produces $62.5 \%$ followed by Hydro Power producing around $12.3 \%$, Nuclear producing $1.8 \%$ and the Renewable Energy Sources producing around $23.7 \%$ of the total installed capacity [5].

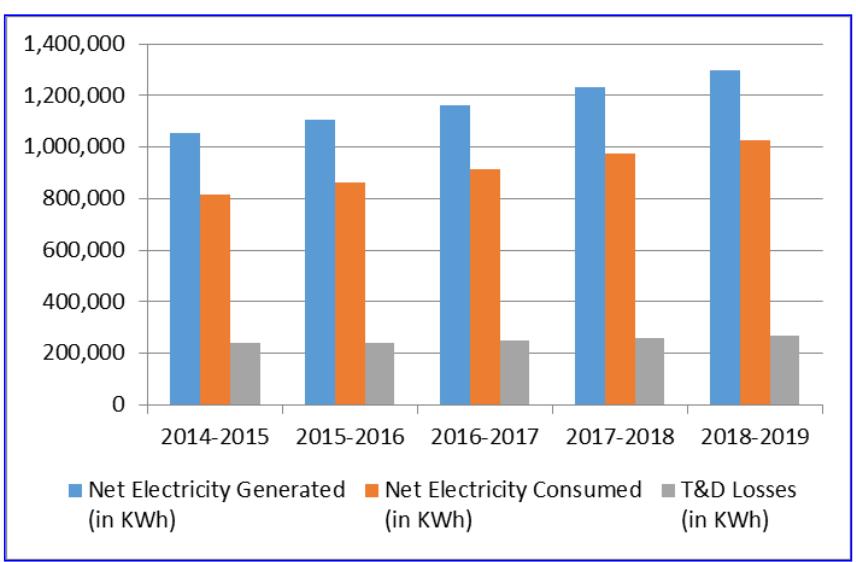

Fig. 1: Power Generation versus consumption in India

The financial year 2019-2020 saw an overall increase of $0.95 \%$ when compared to 2018-2019. The overall Power Supply Position of the country is at a deficit of $-0.5 \%$ against the requirement of 12,91,010 Mega Units (MU) and availability of $12,84,444$ MU. The Per Capita power consumption of India as of 2018-2019 is $1182 \mathrm{KWh}$ against the world average of $3110 \mathrm{KWh}$. The industrial consumption is at $41.16 \%$ against the residential consumption of $24.76 \%$, agricultural consumption of 17.69 and commercial consumption at $8.24 \%$. The total transmission and Distribution losses in India are around 18\% as of 2019 [5].

\section{POWER MANAGEMENT SYSTEM IN INDIA}

The most important aspect of power generation is the transmission because only an effective transmission can fulfill the needs of an end user. The above flow graph depicts the power flow model followed in India. The power management system is a series of policy framework, processes and procedures to manage the energy usage. Energy Management System (EMS) helps in maximizing profits by reducing costs and enhancing efficiency of the system. An EMS integrates application software such as state estimation, contingency analysis, automatic generation control, and economic dispatch.



Fig. 2: Existing Power Management System in India

The newly developed smart grid infrastructure of the Indian power management system is a structural hierarchy comprising the National Load Dispatch Centers (NLDC); Regional Load Dispatch Centers (RLDC); State Load Dispatch Centers (SLDCs); Sub-Load Dispatch Centers (Sub-LDC) and Distribution Control Centers (DCC).

Power system is monitored at multi levels and EMS systems at each level are integrated. It is supported by the synchrophasor technology for monitoring of large power system with accuracy [5]. The number of Phasor Measurement Units (PMUs) installed across the power grids are increasing. India had up to 77 PMUs installed by 2017 with better visualization tools and usage of synchrophasers for real time operation by the system operator. Synchrophasers in control rooms have been beneficial for both real-time dispatch and post-dispatch analysis. It provides a large amount of data being sent to the control centres/system protection centres. With the synchrophaser technology and the conventional Supervisory Control and Data Acquisition (SCADA) system, power system operators have gained better visibility and enhanced decision making skills.

\section{PROPOSED POWER MANAGEMENT MODEL}

The proposed model is an integrated architecture with flexible and standardized method of data sharing. It shall serve as an open platform for implementing intelligent functionalities. This framework has an interconnection of all monitoring, regulation, management, analysis of regulated systems in various control centers and substations. 


\section{International Journal of Engineering Applied Sciences and Technology, 2020 \\ Vol. 5, Issue 8, ISSN No. 2455-2143, Pages 292-296 \\ Published Online December 2020 in IJEAST (http://www.ijeast.com)}

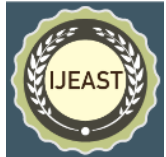

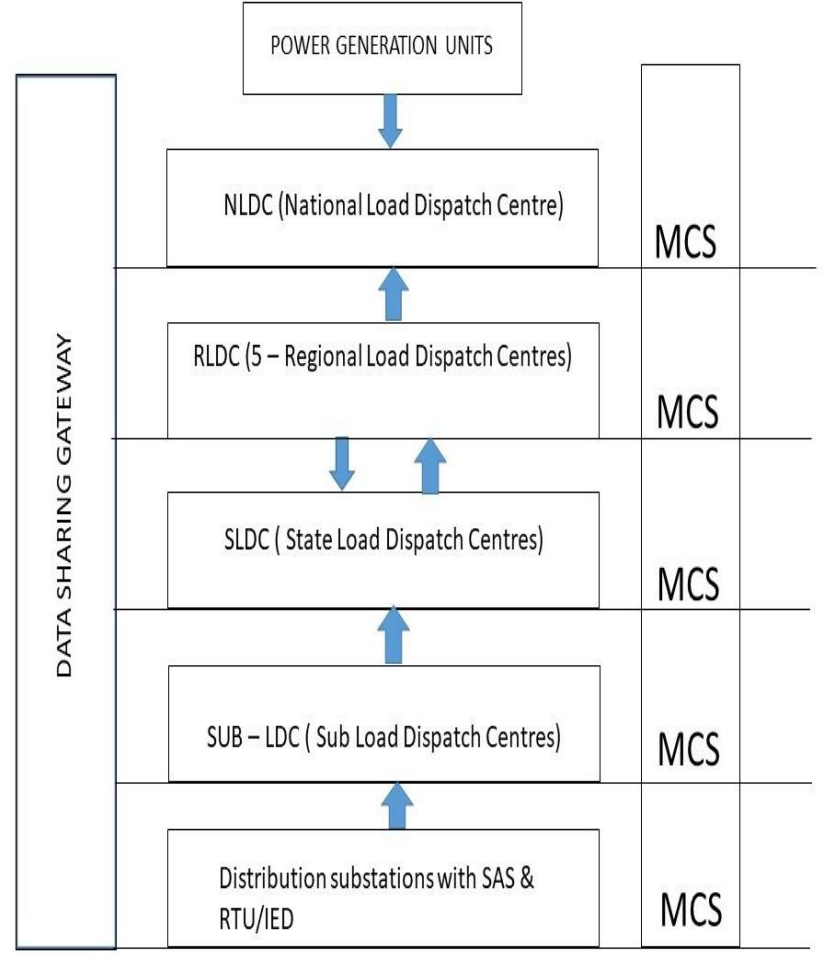

Fig. 3: Integrated System for Data Sharing.

The proposed model is an elaboration on the already existing model according to the need of urgency of the new framework. The country has currently 77 PMUs installed and the number of this installation across the power grid is increasing day by day. This enables real-time monitoring of large power systems and also availability of large amount of data [6]. The problem is data analysis and full-fledge translation of available data into practical situations.

\section{A. MAIN SYSTEM}

The proposed system modularizes each level as a subsystem. Each subsystem has a separate Monitoring and Control Systems (MCS) which enables it to take independent decisions. Its major features are on-line monitoring, automatic control, operational analysis and decision making; primarily emphasizing on execution and thinking. It essentially coordinates and collaborate closed loop control and manage operations of Power Grid.

The key technology implemented is the Data Sharing Gateway. In the conventional data exchange of SCADA/ EMS, in order to provide real time data of one region to other region, data received at NLDC is transferred from NLDC to RLDC on reverse The Inter-control Center Communications Protocol (ICCP) links as reversed data flow. As the SCADA/ EMS systems of regional control centers were installed about 10 years before they are of very old version [7]. ICCP servers of three SCADA systems do not support the transfer of partial dataset. In this case any mismatch in any ICCP ID causes the failure of entire data at remote sites. The mismatch of ICCP ID generally results of different time of on lining of SCADA database. Since, RLDCs acquire data from states; they have to match their on-lining schedule with states. Any change in data at any side causes this type of issue [7]. Hence, an online platform such as Data Sharing Gateway with necessary information security could be a boon. Vertically, data sharing could be enabled between two different levels of control centers such as between substation and control centers and horizontally, any two modules of the same level such as substations or control centers can communicate.

\section{B. DATA SHARING GATEWAY}

A significant feature of the proposed model is the common online data sharing platform easily accessed by all modules with necessary information security. It can also serve in providing the available data with advanced visualization tools for better understanding. The proposed Data sharing gateway can provide sampled and model data and also standardized data collected through the Intelligent Electronic Device's (IED) such as RTU, recorders, protection relay and PMU. It can also provide essential inputs on meteorological geography through Geographic Information System (GIS), risk evaluation, energy supply and responses, and intelligent fault detection with its accurate time stamp.

With the MCS and the data sharing Gateway at different levels; key operators, and control system managers can not only get real time data but also perform calculations and well defined algorithms to get quick results displayed readily on their respective User Interface (UI) to be able to make quick decisions and thus function independently.

\section{USER INTERFACE DASHBOARD}

The UI dashboard would enable simulation, access to previous analysis records of similar outrages in historical summary database and real time operation. With enormous data, and the feasibility of performing standard algorithms, the operator can obtain number of recommended decisions or remedial control actions at multi-stage level for a given outrage and can also model an outrage and simulate the effectiveness before implementing in real time. Moreover, with the help of previous analysis records, operator could check for a similar outrage instances, the decisions implemented, calculate risk and severity and to what extent the fault could be corrected under the various remedial control actions suggested, given the real-time meteorological conditions obtained through the Geographic Information System.

\section{IMPLICATIONS}

The proposed system creates a clear data link between each subsystem thereby enabling efficient data sharing between different levels of control centres. No hampering of the data. It creates an easy access pathway, and provides access to previous analytical records thereby facilitating in resolving problems more effectively with the available data in the historical summary database and real time operations. There is a need for continuous vigilance on the databases for any kind 


\section{International Journal of Engineering Applied Sciences and Technology, 2020 \\ Vol. 5, Issue 8, ISSN No. 2455-2143, Pages 292-296 \\ Published Online December 2020 in IJEAST (http://www.ijeast.com)}

of software failing which, malwares or attack may have to be faced. Cyber security could be one of the prime concerns for implementing such a robust system in India. This system may also call for additional investment but will yield appreciable results.

\section{CONCLUSION}

The traditional SCADA/ EMS have helped operators in making quick decisions to outages. However with the increasing grid complexities in interest of growing demand of energy; conceptual model of an integrated power system framework that enhances systems' efficiency and enables secure and readily available data at all levels is proposed with the objective to increase operational capability. It can help reduce chances of cascaded outages in power systems thus making it more robust and flexible to the growing demand. It is believed that the proposed system would optimize current management system and make it more efficient.

\section{ACKNOWLEDGMENT}

The authors express their profound thanks to the management of Karunya Institute of Technology and Sciences, Coimbatore and Hillgrove Research Pvt. Ltd., Coimbatore acknowledge all the authors and contributors of research articles and other reports which has been referred and cited in this research article. Also, the author thanks the editorial of Hillgrove Research Pvt. Ltd., Coimbatore, for their encouragement and review of this research article.

\section{REFERENCES}

[1] https://www.kuickresearch.com/report-India-PowerTransmission-\&-Distribution-Sector-OpportunityOutlook-2025.php

[2] https://ourworldindata.org/grapher/urban-and-ruralpopulation -2050 ?country= IND

[3] https://en.wikipedia.org/wiki/Electricity_sector_in_India

[4] SahilAli, 2018, THE FUTURE OF INDIAN ELECTRICITY DEMAND - How much, by whom, and under what conditions? October 2018, BROOKINGS INDIA , INDIA

[5] NATIONAL STATISTICAL OFFICE, 2020, ENERGY STATISTICS 2020,Twenty Seventh Issue, MINISTRY OF STATISTICS AND PROGRAMME IMPLEMENTATION GOVERNMENT OF INDIA, 6070, 2020, New Delhi

[6] Manas Kumar Jena \& B.K Panigrahi, 2017, Dynamic Stress Assessment in Power Transmission Network to Support Wide Area Early Warning System, IEEE, 2017, ISBN No: 978-1-5386-4319-8
[7] V. K. Agrawal, P. K. Agarwal, Harish Kumar Rathour, Anamika Sharma\& Akhil Singhal, 2014, Experience of Integrated Operation of SCADA/EMS System at National Level - A Case Study, NPSC-IITK, IEEE 2014, ISBN No: 978-1-4799-5141-3 